Note

\title{
Toxicity of Five Fungicides Against the Ciliate Colpoda aspera
}

\author{
NORIHIDE KAKIICHI*, HIROSHI MATSUMOTO, NAMIKO NIHEI, \\ MUNEYOSHI MANO, YOSHIE ANDO, AYAKO KABUTOYA, \\ AND SHIN-ICHI KAMATA \\ Department of Veterinary Hygiene, Nippon Veterinary and Animal Science University, \\ Musashino-shi Tokyo 180, Japan
}

Received 16 April 1997/Accepted 29 August 1997

\begin{abstract}
The acute toxicity levels of $\mathbf{5}$ kinds of fungicide against the free-living protozoal ciliate Colpoda aspera were tested in cocultivation with Alcaligenes faecalis IF013111. The fungicides used were products containing the following effective components: dimethilimol (DMM), admixture of ziram, thiram and polyoxin (ZTP), flutolanil (FLN), streptomycin (SM), or 8hydroxyquinoline copper and captan (CHC). Each fungicide was added at varying concentrations, and the effective concentration $\left(E C_{50}\right)$ at which the specific growth rate of $C$. aspera was reduced to $50 \%$ after $24 \mathrm{~h}$ culture was defined as the acute toxicity of the fungicide tested. It was found that ZTP had the highest level of toxicity, followed by CHC, SM, DMM and FLN. When the fungicides were evaluated in terms of safety on the basis of indices obtained by dividing normally applicable concentrations (NC) by $\mathrm{EC}_{50}$, the safety levels of SM, DMM and FLN were high compared to those of ZTP and CHC.
\end{abstract}

Key words : Colpoda aspera/Fungicide/Toxicity/Median effective concentration.

Various fungicides are used in agricultural production for the prevention of a productivity drop caused by pathogenic microorganisms. If the fungicides used are washed out with rain water into the soil and bodies of water, ecological systems may be affected. Among microfauna, protozoal ciliates are known to be helpful in the purification of water.

A variety of methods have been introduced to test the acute toxicity of poisons on free-living protozoal ciliates (Kakiichi,1993b; Persoone and Dive, 1978). We previously tested the acute toxicity of 13 kinds of disinfectant and 13 kinds of insecticide against the ciliate Colpoda aspera in cocultivation with Alcaligenes faecalis (Kakiichi et al., 1991, 1993b, 1995, 1996). The median effective concentration $\left(\mathrm{EC}_{50}\right)$ at which the specific growth rate of this ciliate

*Corresponding author. Tel: +81-0422-31-4151 (Ext. 257), Fax: +81-0422-33-2094. was decreased to $50 \%$ was defined as the acute toxicity (Huber et al, 1990; Kakiichi et al, 1993a; Persoone and Dive, 1978). Reasons why acute toxicity were based on $\mathrm{EC}_{50}$ were explained in our previous reports (Kakiichi et al., 1991, 1993b,1995, 1996). This study was performed to examine the acute toxicity of fungicides against the ciliate $C$. aspera for the environmental protection of water bodies.

The following 5 kinds of fungicide were used: Milcarb ${ }^{\circledR}$, Polymet-P ${ }^{\circledR}$, Moncut ${ }^{\circledR}$, Phytomycin ${ }^{\circledR}$ and Fujiokishiran ${ }^{\circledR}$ of Nihon Nohyaku Co., Ltd. Milcarb is a liquid preparation containing $12.5 \%(\mathrm{~W} / \mathrm{V})$ dimethilimol (DMM). Polymet- $P$ is a wettable powder preparation containing $41 \%(\mathrm{w} / \mathrm{w})$ ziram, 25\% (w/ $\mathrm{W})$ thiram and $5 \%(\mathrm{w} / \mathrm{W})$ polyoxin (ZTP). Moncut is a wettable powder preparation containing 25\% (w/ w) flutolanil (FLN). Phytomycin is a liquid preparation containing 5\% ( $\mathrm{W} / \mathrm{v})$ streptomycin $(\mathrm{SM})$. Fujiokishiran is a wettable powder preparation containing 
$30 \%(w / w)$ 8-hydroxyquinoline copperand 20\% (w /w) captan ( $\mathrm{CHC})$.

The ciliate Colpoda aspera was isolated from activated sludge at our laboratory. Cocultivation with Alcaligenes faecalis IFO 13111 was carried out using an egg-lettuce medium (EL medium) (Curds,1963; Kakiichi et al., 1991; Sudo and Aiba, 1971). The same methods as described previously (Kakiichi et al., 1991, 1993b, 1995, 1996) were used for the storage and growth culture of $A$. faecalis and $C$. aspera.

The minimum inhibitory concentrations (MICs) of the fungicides against $A$. faecalis were determined as previously described (Kakiichi et al., 1991, 1993b, 1995, 1996). The toxicity tests of the fungicides against $C$. aspera were carried out by the methods previously described (Kakiichi, 1993a).

The concentrations of the fungicides used in this experiment represent the percent contents of the principal ingredient(s) as mentioned above. For example, $\mathrm{EC}_{10}$ and $\mathrm{EC}_{50}$ of Milcarb against $C$. aspera and its MIC against $A$. faecalis were determined on the basis of the DMM content $(12.5 \%, \mathrm{w} / \mathrm{v})$ of this fungicide. For the mixture preparations containing two or three kinds of ingredients, corresponding values were determined on the basis of the total content of the principal ingredients. Regarding Porymet- $P$, for example, the total content of the principal ingredients was $71 \%(\mathrm{w} / \mathrm{w})$ ( $41 \%$ ziram, $25 \%$ thiram and $5 \%$ polyoxin).

A method for calculating $\mathrm{EC}_{50}$ has been described in detail (Kakiichi, 1993a; Kakiichi et al., 1991). The specific growth rates of $C$. aspera in media containing different concentrations of fungicides $\left(\mu_{\text {tox }}\right)$ and in those containing none ( $\mu_{\text {cont }}$ ) were applied to calculate $\mathrm{EC}_{50}$ and $\mathrm{EC}_{10}$, the concentrations at which $\mu_{\text {cont }}$ was decreased to $50 \%$ and by $10 \%$, respectively.

Table 1 shows the $\mathrm{EC}_{50}$ and $\mathrm{EC}_{10}$ against $C$. aspera and the MIC against $A$. faecalis for the 5 fungicides. ZTP had the lowest value of both $\mathrm{EC}_{10}$ and $\mathrm{EC}_{50}$ against $C$. aspera. It was followed in order by $\mathrm{CHC}$, $\mathrm{SM}, \mathrm{DMM}$ and FLN. ZTP also had the lowest MIC against $A$. faecalis. It was followed in order by $\mathrm{SM}$, $\mathrm{DMM}, \mathrm{CHC}$ and FLN. The MIC/EC 50 value of SM was 1.3 , but the corresponding values of the other fungicides were greater than 3.5. An $\mathrm{EC}_{50}$ test for $C$. aspera was achieved by calculation of the specific growth rates of $C$. aspera in cocultivation with $A$. faecalis. If the $\mathrm{MIC}$ against $A$. faecalis and $\mathrm{EC}_{50}$ against $C$. aspera were close in value, it was likely that the $E_{50}$ value did not represent $E_{50}$ resulting from the direct toxic action of the fungicide used, but could be interpreted as reflecting the decrease or death of the bacteria on

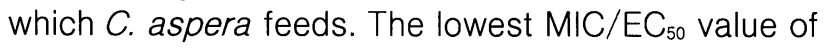

TABLE 1. $\mathrm{EC}_{10}$ and $\mathrm{EC}_{50}$ against $C$. aspera and $\mathrm{MIC}$ against $A$. faecalis for five fungicides.

\begin{tabular}{lrrrr}
\hline \multirow{2}{*}{ Fungicide } & \multicolumn{2}{c}{ C. aspera } & & A. faecalis \\
\cline { 2 - 3 } Dimethirimol & $\mathrm{EC}_{10}{ }^{a}(\mathrm{mg} / \mathrm{l})$ & $\mathrm{EC}_{50}{ }^{a}(\mathrm{mg} / \mathrm{l})$ & $\mathrm{MIC}(\mathrm{mg} / \mathrm{l})$ \\
Ziram + Thiram + Polyoxin & $0.16 \pm 0.27 \pm 11.65$ & $201.56 \pm 23.86$ & 700 \\
Flutolanil & $212.52 \pm 12.95$ & $445.11 \pm 28.61$ & 20 \\
Streptomycin & $33.82 \pm 6.54$ & $78.16 \pm 9.95$ & $>25,000$ \\
8-Hydroxiquinoline copper & $0.48 \pm 0.04$ & $1.53 \pm 0.24$ & 100 \\
$\quad$ + Captan & & & 1,000 \\
\hline
\end{tabular}

${ }^{a}$ Values are mean \pm S.D.

TABLE 2. Relationship between the normal applicable concentration (NC) and the $E_{50}$ of five fungicides.

\begin{tabular}{|c|c|c|c|}
\hline \multirow{2}{*}{ Fungicide } & $\mathrm{NC}$ & $\mathrm{EC}_{50}$ & Dilution ${ }^{a}$ \\
\hline & $\mathrm{mg} / \mathrm{l}$ & $\mathrm{mg} / \mathrm{l}$ & $\mathrm{NC} / \mathrm{EC}_{50}$ \\
\hline Dimethirimol & $42-1,250$ & 201.6 & $>0.2-6.2$ \\
\hline Ziram + Thiram + Polyoxin & 875 & 0.8 & $>1,094$ \\
\hline Flutolanil & $250-5,000$ & 445.1 & $>0.5-11.2$ \\
\hline Streptomycin & 125 & 78.2 & $>1.6$ \\
\hline $\begin{array}{l}\text { 8-Hydroxiquinoline copper } \\
\text { + Captan }\end{array}$ & $625-1,250$ & 1.5 & $>417-833$ \\
\hline
\end{tabular}

${ }^{a}$ Dilution required to keep concentration below $\mathrm{EC}_{50}$. 
$S M$ may lead to the presumption that $E_{50}$ of $S M$ against $C$. aspera reflects the inhibitory influence of SM against $A$. faecalis. This suggested that determination of MIC against bacteria that are used as food is necessary when determination of $\mathrm{EC}_{50}$ against ciliates is undertaken in cocultivation with the bacteria.

Table 2 shows the relation between the normal applicable concentration (NC) and $\mathrm{EC}_{50}$ of the 5 fungicides. The safety of the fungicides was assessed by dividing $N C$ by $E C_{50}$. Safety increases with the decrease in $\mathrm{NC} / \mathrm{EC}_{50}$. On calculating $\mathrm{NC} / \mathrm{EC}_{50}$ ratios using the highest $\mathrm{NC}$ values, $\mathrm{SM}$ had the lowest value. It was followed in order by DMM, FLN, CHC and ZTP. $S M, D M M$ and FLN were relatively safe fungicides.

Of the fungicides used in this study, only thiram, a constituent component of ZTP, had been tested previously, and its minimum active dose (MAD) against Colpidium campylum had been reported to be $0.3 \mathrm{mg}$ $/ l$ (Dive and Leclerc, 1975). The $48 h-L C_{50}$ of ziram, thiram and polyoxin against Oryzias latipes have been reported to be $0.056,75$ and $>40 \mathrm{mg} / l$, respectively, and their $3 \mathrm{~h}-\mathrm{LC}_{50}$ against Daphnia pulex to be 0.45 , $10-23$ and $>40 \mathrm{mg} / l$, respectively (Nishiuchi, 1983 ; Tanaka, 1978). Frear and Boyd (1967) described the $24 \mathrm{~h}-\mathrm{LC}_{50}$ of ziram and thiram against Daphnia magna to be 0.016 and $1.30 \mathrm{mg} / l$, respectively. The toxicity levels of ziram, thiram and polyoxin against fish are ranked $\mathrm{C}, \mathrm{B}$ and $\mathrm{A}$, respectively (Nihon Nohyaku Co., Ltd., 1995). Of the 3 fungicides, ziram has the highest toxicity against aquatic animals. Of the 5 fungicides used in this study, ZTP had the lowest $\mathrm{EC}_{50}$ against $C$. aspera Ziram was presumed to have largely contributed to the high toxicity of ZTP.

The $48 \mathrm{~h}-\mathrm{LC}_{50}$ of $\mathrm{DMM}$ against $O$. latipes, its $3 \mathrm{~h}$ $\mathrm{LC}_{50}$ against $D$. pulex and its $48 \mathrm{~h}-\mathrm{LC}_{60}$ against Sympetrum frequens in the larval stage have been reported to be 74,350 and $>40 \mathrm{mg} / l$, respectively (Nishiuchi, 1983; Tanaka, 1978). DMM is ranked A in the toxicity list (Nihon Nohyaku Co., Ltd., 1995). The $E_{50}(201.6 \mathrm{mg} / l)$ of DMM against $C$. aspera is close to its $3 \mathrm{~h}-\mathrm{LC}_{50}$ against $D$. pulex, and DMM seems to have a low toxicity against aquatic animals. The fishtoxicity of FLN is in the B rank. The $48 \mathrm{~h}-\mathrm{LC}_{50}$ of FLN against Cyprinus carpio has been reported to be 2.4 $\mathrm{mg} / \mathrm{l}$ (Nihon Nohyaku Co., Ltd., 1995). FLN seems to have a lower toxicity against $C$. aspera than against fish, because its $\mathrm{EC}_{50}$ against $C$. aspera was high (445 $\mathrm{mg} / l$ ).

SM is an antibiotic effective against gram-positive and -negative bacteria and ineffective against anaerobic bacteria. The fish-toxicity of SM is in the A rank, and its $48 \mathrm{~h}-\mathrm{LC}_{50}$ against $C$. carpio and $O$. latipes have been reported to be both $>40 \mathrm{mg} / l$ and its $3 \mathrm{~h}-\mathrm{L} \mathrm{C}_{50}$ against $D$. pulex to be $>40 \mathrm{mg} / l$ (Nihon Nohyaku
Co., Ltd., 1995; Nishiuchi, 1983; Tanaka, 1978). The $\mathrm{EC}_{50}$ of $\mathrm{SM}$ against $C$. aspera was $78.2 \mathrm{mg} / l$ in this study. This $\mathrm{EC}_{50}$ level might have resulted from the bactericidal activity of SM against $A$. faecalis which served as food for $C$. aspera. From this, SM is presumed to have only a minor impact on aquatic animals.

$\mathrm{CHC}$ is an admixture of captan and 8hydroxyquinoline copper. These are both ranked $C$ in the fish-toxicity table and exert a strong effect on aquatic animals. The $48 \mathrm{~h}-\mathrm{LC}_{50} \mathrm{~S}$ of captan against $C$. carpio, $O$. latipes and $S$. frequens of the larval stage have been reported to be $0.25,1.0-2.2$ and $>1,000$ $\mathrm{mg} / l$, respectively, and its $3 \mathrm{~h}-\mathrm{LC}_{50}$ against $D$. pulex to range from 5.5 to $8.4 \mathrm{mg} / l$ (Nihon Nohyaku Co., Ltd., 1995; Nishiuchi, 1983; Tanaka, 1978). Frear and Boyd (1967) reported that the $26 \mathrm{~h}-\mathrm{LC}_{50}$ of captan against $D$. magna was $1.30 \mathrm{mg} / l$. The $48 \mathrm{~h}-\mathrm{LC}_{50} \mathrm{~S}$ of 8 hydroxyquinoline cooper against $O$. carpio and 0 . latipes have been reported to be 0.18 and $0.08 \mathrm{mg} / l$, respectively (N1ihon Nohyaku Co., Ltd., 1995; Nishiuchi, 1983). This fungicide has been described as having a $3 \mathrm{~h}-\mathrm{LC}_{50}$ value of $10-23 \mathrm{mg} / l$ against $D$. pulex and a $48 \mathrm{~h}-\mathrm{LC}_{50}$ value of $>40 \mathrm{mg} / l$ against $S$. frequens (Nishiuchi, 1983; Tanaka, 1978). The $E_{50}$ of $\mathrm{CHC}$ against $C$. aspera was $1.53 \mathrm{mg} / l$ in this study. This suggests that $\mathrm{CHC}$ has the highest toxicity against fish, approximately the same degree of toxicity against ciliates and water fleas and the lowest toxicity against insects.

The results of this study have shown that ZTP had the highest toxicity against $C$. aspera, followed in order by $\mathrm{CHC}, \mathrm{SM}, \mathrm{DMM}$ and $\mathrm{FLN}$. The safety levels of SM, FLN and DMM were almost equally high and those of ZTP and $\mathrm{CHC}$ were low. These findings suggest that adequate caution is required to prevent the flow of ZTP and $\mathrm{CHC}$ into bodies of water.

\section{ACKNOWLEDGMENT}

The authors wish to thank Nihon Nohyaku Co., Ltd. for providing the fungicides used in this study.

\section{REFERENCES}

Curds, C. R. (1963) The flocculation of suspended matter by Paramecium caudatum. J. Gen. Microbiol., 33, 357-363.

Dive, D., and Leclerc, H. (1975) Standardized test method using protozoa for measuring water pollutant toxicity. Prog. Wat. Technol., 7, 67-72.

Dive, D., Leclerc, H., and Persoone, G. (1980) Pesticide toxicity on the ciliate protozoan Colpidium campylum: Possible consequences of 
the effect of pesticides in the aquatic environment. Toxicol. Environ. Safety, 4, 129-133.

Frear, D. E. H., and Boyd, J. E. (1967) Use of Daphnia magna for the microbioassay of pesticides. I. Development of standardized techniques for rearing Daphnia and preparation of dosage-motality curves for pesticides. J. Econom. Entomol., 60, 1228-1236.

Huber, H. C. H., Huber, W., and Ritter, V. (1990) Simple bioassays for evaluating toxicity of environmental chemical using microcultures of human peripheral blood lymphocytes and monoxenic cultures of the ciliate Tetrahymena pyriformis. Zbl. Hyg., 189, 511-526.

Kakiichi, N., Sato, M., Yamamoto, T., Kamata, S., Ito, O., Hayashi, M., Komine, K., Otsuka, H., and Uchida, K. (1991) Toxicity test for invert soap against ciliate Colpoda aspera. Anim. Sci. Technol., $62,113-119$.

Kakiichi, N. (1993a) Toxicity and evaluation of disinfectants on activated sludge and protozoa (in Japanese). Bokin-Bobai, 21, 347-356.

Kakiichi, N., Yamamoto, T., Kamata, S., Otsuka, H., and Uchida, K. (1993b) Effect of anphoteric surfactant biguanide compounds and orthodichlorobenzene preparation on the specific growth rate of ciliate Colpoda aspera. Anim. Sci. Technol., 64, 1013-1016.

Kakiichi, N., Yamamoto, T., Kamata, S., Komine, K., and Otsuka, H. (1995) Toxicity of sodium hypochlorite, sodium dichloroisocyanurate, iodophors, formaldehyde and glutaraldehyde against ciliate Colpoda aspera. Bokin-Bobai, 23, 669-673.

Kakiichi, N., Kitamikado, A., Sasamori, T., Tanaka, Y., Ishiwata, Y., Sakurai, A., Shimizu, K., and Kamata, S. (1996) Toxicity of several insecticides against ciliate Colpoda aspera. Anim. Sci. Technol., 67, 844-856.

Nihon Nohyaku Co., Ltd. (1995) Toxicity list of agricultural medicines (in Japanese). In List of Agricultural Medicines, pp. 263-268, Tokyo.

Nishiuchi, Y. (1983) Aquatic animal and agricultural medicines, continued (in Japanese). pp. 98-155, Scientist Inc., Tokyo.

Persoone, G., and Dive, D. (1978) Toxicity tests on ciliates. Ecotoxicol. Environ. Safety, 2 , 105-114.

Sudo, R., and Aiba, S. (1971) Growth rate of Vorticellidae isolated from activated sludge. Jpn. J. Ecol., 21, 70-76.

Tanaka, J. (1978) Aquatic animal and agricultural medicines (in Japanese). pp.153-184, Scientist Inc., Tokyo. 